Editorial

\title{
Airlift Maintenance and Sustainment: The Indirect Costs
}

\author{
Kyriakos I. Kourousis $\mathbb{D}$ \\ School of Engineering, University of Limerick, V94 T9PX Limerick, Ireland; kyriakos.kourousis@ul.ie
}

Received: 30 August 2020; Accepted: 2 September 2020; Published: 2 September 2020

\begin{abstract}
This article aims to present and discuss a set of technical matters affecting the maintenance and sustainment cost of military transport aircraft (airlifters). An overview of the military aviation technical support system is provided, in conjunction with a high level discussion on the life cycle cost. Four technical support pillars are defined as part of this analysis: supply, restoration and upgrade, engineering and regulatory compliance. A focused discussion on airlift sustainment factors, based on past experience, is used to identify technical considerations that can be used for the evaluation of new aircraft. A number of technical considerations which are key for cost purposes are identified and mapped against the defined technical support pillars, related to engineering and technical support and airworthiness management aspects. Important practical technical considerations are identified, discussed and critiqued under an independent lens. This article can stimulate discussion of the maintenance and sustainment costs of airlifters, both within military aviation operators and the defence industry community but also within the civil aircraft maintenance industry.
\end{abstract}

Keywords: aircraft maintenance; airworthiness; military aviation; airlift; cost

\section{Technical Support in Military Aviation}

The technical support system in the United States and European military aviation is typically structured as organisational (squadron level), intermediate (base level) and depot level maintenance. Looking at the different functions within these segments, one can identify technical activities broadly covering:

- Supply of material (aircraft components, parts, consumables, etc.) in support of maintenance tasks, at organisational $(\mathrm{O})$ and intermediate (I) level, where the focus is on the military operational unit.

- Restoration and upgrade at depot (D) level, where overhaul takes place and, in general, any technical (maintenance) activity beyond the capability of the base and the squadron. This includes shop-level maintenance for components and engine overhaul.

- Engineering, in terms of services provided for resolving problems, designing, approving, assessing and implementing engineering changes.

- Regulatory compliance spans across all activities and accompanies oversight at the various levels of command. However, often, in military aviation, the role of the regulator is not completely independent of the chain of operational command [1], unlike civil aviation.

These technical support pillars (supply, restoration and upgrade, engineering and regulatory compliance) are intended to sustain the airworthiness and the operational capability of a military aircraft fleet. Operational readiness and utilisation (including training) interact with all facets of maintenance at all levels (I, $\mathrm{O}$ and $\mathrm{D}$ ), since the objective of technical support is to supply mission ready aircraft. In turn, operational readiness has an impact and it is affected by grounding time. This simplified view of the military aircraft maintenance and sustainment system is illustrated in Figure 1. 


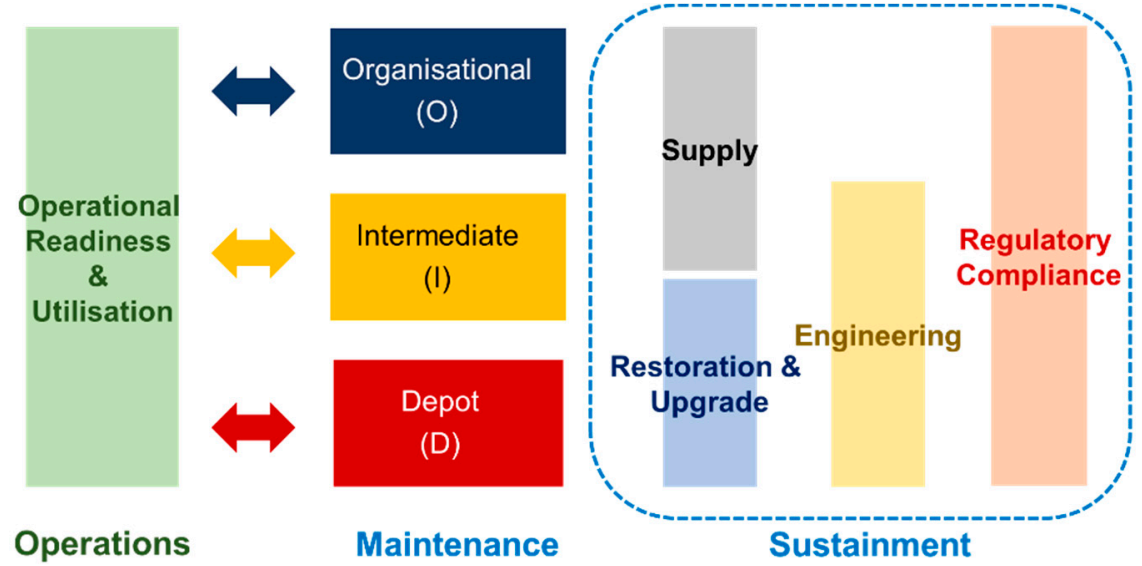

Figure 1. The different elements of a maintenance and sustainment (technical support) system for military aircraft and their interactions with operational readiness and utilisation.

\section{Life Cycle Cost}

As with every technical system, a military aircraft is designed, and expected to be operated, over a specified life cycle. An operator needs to ensure that the aircraft fleet remains healthy (airworthy) and operationally capable throughout its life. Complex maintenance and sustainment activities are performed to ensure that the aircraft systems operate reliably, structural integrity is assured and upgrades allow it to offer value to the operational capabilities of the defence force. The cost associated with maintenance and sustainment is continuously evolving, and it is generally expected to increase over time. The focus of the discussion is not how this cost evolves but the indirect costs associated with the ownership of military aircraft and particularly military transport aircraft (airlifters).

Military operators may set a lower (start) point and an upper (cut-off) point for the operating cost, both for monitoring/management and decision-making purposes. These two points define the acceptable operating margins for an aircraft fleet. The life cycle can be segmented, in broad terms, into four phases: the initial investment, the learning and maturing phase, the maturity phase and the end of life (disposal) of the aircraft (Figure 2).

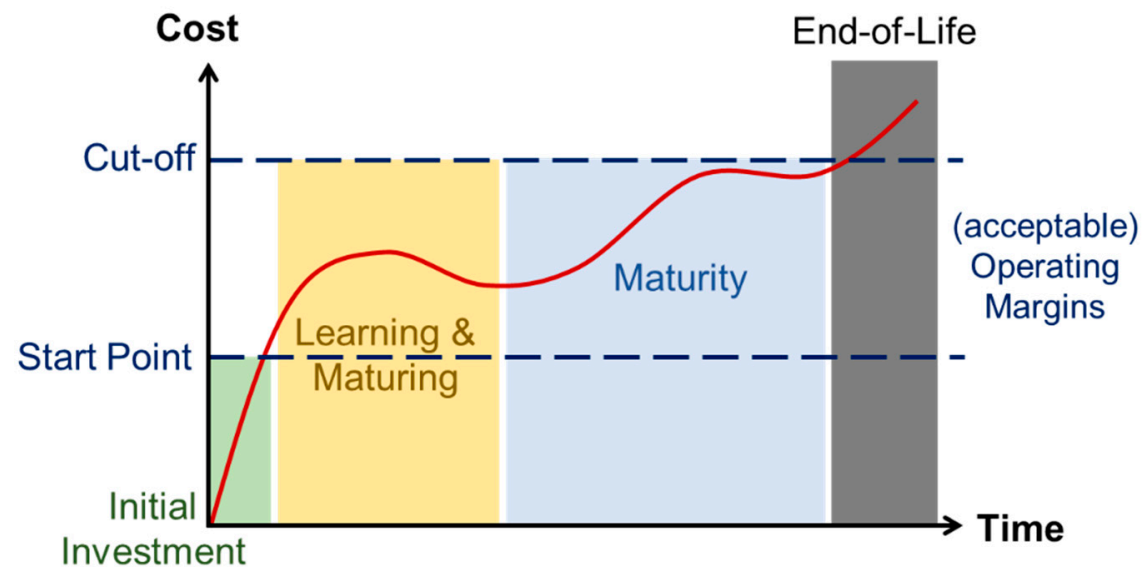

Figure 2. Life cycle, in phases, of military aircraft.

Entry to service requires an initial investment, which accompanies/stems from the procurement contract for new systems. The level of initial investment defines the start point in the cost curve, with costs in this phase associated with:

- Technical training for the engineering and technical staff; 
- Development of maintenance capability, at different levels and depending on what or how an operator wishes to utilise the aircraft (i.e., configuration, mission profiles, etc.);

- Acquisition or preparation of the necessary infrastructure for maintenance, logistics support and operation of the fleet.

The next phase in the life of aircraft, which may be the most challenging in terms of managing some uncertainty around the performance of a new system, is that of learning and maturing. Inexperienced/smaller operators with fewer resources than larger defence forces may face additional challenges. For example, small operators typically do not have a sufficient level of depth in engineering expertise or in-house technical resources which would help them in resolving early-life challenges. In this phase, the operator needs to:

- Build up its engineering capability and expertise at various levels. This involves a direct or indirect investment in technical knowledge, acquired through training/retraining or obtaining experience from the manufacturer via technical support services. Strategies to retain this expertise in the long term are important, as engineering and technical staff engaged in this phase obtain valuable first-hand experience from their interaction with the manufacturer.

- Develop or adjust the logistics support. A technical supply system needs to be established for the new aircraft, in most cases, working in sync with follow on support (FOS) contracts and existing structures for other aircraft types of the defence force.

- Establish contract management structures and train staff to perform combined engineering and supply functions, in an integrated logistics support (ILS) or programme office environment. This set of activities is not only time consuming but also creates value and/or waste within the overall technical system.

The maturity phase may need more attention than the learning and maturing phase. As the technical system (aircraft) ages, it can become more resilient or predictable, but the ageing effects will start to have an impact on integrity or reliability at the same time. This can be a very interesting period for engineers, since older aircraft offer new challenges. Typically, this phase includes:

- Major maintenance tasks arising from the evolving maintenance programmes (often dictated by the manufacturers and/or operators).

- Major structural repairs mandated to rectify findings from inspections performed to monitor the effects of fatigue and corrosion.

- Enhanced focus on risk management since there is always a need for unobstructed operations. The aircraft fleet is required to operate under the same profiles it was procured for, rather than imposing operations restrictions or limiting its specifications to meet engineering/technical issues.

- Management of obsolescence, which presents additional challenges for the supply and operational capability of some of the systems of the aircraft.

- Aircraft upgrades, by default, large-scale engineering change activities, involving and complemented by heavy maintenance tasks. Upgrades introduce new features to the aircraft or improve the existing systems' functionality, integrity and reliability, i.e., structural fatigue mitigation, replacement of electrical wiring and other degraded components, etc.

When the upper (cut-off) point is reached (or exceeded in some cases), the decision-makers may place the aircraft at the of end-of-life phase, leading to disposal, storage or decommissioning. Often, these decisions are made on the basis of operational and/or political reasons.

\section{Airlift Sustainment}

A number of factors have a positive (increasing) contribution to the sustainment cost for military transport aircraft. Some of these factors are also applicable to other military aircraft types. These are discussed here. 


\subsection{Diverse and Non-Typical Operations}

The nature of the military aircraft operations is dictating or imposing diverse and often non-typical (when comparing to civil transport aircraft) mission profiles and operating environment. This, in turn, has an effect on the cost of sustainment, since the maintenance programme needs to capture proactively any problems that may reduce the reliability of the aircraft systems.

\subsection{Reliance on Offshore Maintenance Services}

Heavy (depot-level) maintenance and, in some cases, intermediate-level maintenance, may have to be performed at overseas maintenance centres. This is the case when such capability has not been developed in-house (within the defence force organisation or at in-country aircraft maintenance organisations). Military operators have to rely on this set of services, which, in the long term, can have a substantial impact on sustainment cost. This includes out of country capabilities, offered by commercial entities. An example of specialised maintenance providers for airlifters is the Marshall Aerospace and Defence Group in the United Kingdom, which has extensive maintenance capabilities on the Lockheed Martin C-130 aircraft platform [2].

\subsection{Disconnect between Military and Civil Airworthiness Requirements}

Civil and military aviation are, by default, not aligned or consistent with each other, in terms of both regulations and practice. There are good reasons for this different treatment, primarily attributed to the nature of the operation of the military transport aircraft. This disconnect creates complexities and imposes defence-specific requirements for the preservation of the continuing airworthiness of the aircraft, even when the same aircraft type has dual (civil-military) certification. For example, military transport aircraft may have to be retrofitted with defence-specific equipment, such as chaff and flare dispensers (for self-protection purposes). This equipment cannot be certified under a civil regulatory framework and this activity adds cost for the military aircraft owner/operator.

\subsection{Lack of Civil Type Certificate}

Type certification of some airlifters does adhere to civil (i.e., the European Aviation Safety Agency, EASA, or the Federal Aviation Authority, FAA) regulations. The Airbus A400 M is a relatively recent example of a civil (EASA) certified airlifter [3]. However, for most types, this is not the case. This may have a smaller impact on cost, though modern safety regulations (and certification standards) for civil aircraft have progressively evolved to become more user-friendly, meaning higher efficiencies and improved reliability, resulting in lower long-term sustainment costs.

\subsection{Legacy Structural Design}

Design, especially structural, for many military transport aircraft have evolved (to a small or larger extent) from previous legacy versions. There are many examples, such as the Leonardo C-27J, which is an evolution of the FIAT G.222. Legacy design standards are, in general, less cost-effective than modern standards, as less efficient maintainability and reliability standards and practices are employed. This, in turn, has a toll on the structural maintenance and sustainment cost, since a higher volume and/or more frequent inspections and repairs may be required.

\subsection{Ageing and Obsolescence}

Due to the tendency to utilise military transport aircraft for longer than originally projected, ageing and obsolescence are becoming more profound challenges. Both have to be taken into consideration when evaluating for the acquisition of older (pre-owned), yet more affordable, airlifters. This, however, has to be examined in conjunction with the sought operational requirements, the operational tempo and the anticipated life cycle. An operator may utilise efficiently, within their budget, older aircraft with a good service history and a good structural condition, for five or even ten years. The recent example 
of the United States (US) Navy procurement of an ex-Royal Air Force (RAF) C-130J for \$30 million (in comparison to the cost of $\$ 80$ million for a new aircraft) is characteristic [4].

\subsection{Ongoing Major Maintenance}

Airlifters are large, complex platforms, with many components and parts highly susceptible to ageing effects: fatigue, corrosion, degradation and wear. Operators tend to use these aircraft under harsh conditions and environments. The manufacturers are aware of these issues, developing solutions which are reflected in the maintenance programmes. Maintenance programmes progressively become more thorough and demanding, dictating (higher cost) major inspection and maintenance tasks to sustain the airworthiness of aircraft being operated from their primary base and of those deployed elsewhere.

\subsection{Upgrade}

Upgrades are common for military aircraft, including airlifts. Avionics' and cockpit modernisation programmes, both for operational and technical reasons (some of them related to tackling obsolescence and reliability issues), are popular among operators. These kinds of programmes add value to older fleets by enhancing operational capabilities and/or extending service life. The Lockheed Martin C-130 serves as a good example, with the Hellenic Air Force $\mathrm{C}-130 \mathrm{H}$ and $-\mathrm{B}$ fleet avionics upgrade programme (AUP) in 2002 offering an indication in the costs involved-a 15 aircraft fleet upgrade at a cost of $\$ 6$ million per aircraft [5].

These cost-raising factors are commonly observed in combination, especially in older fleets. The case of the Lockheed Martin C-130's structural integrity offers a good example. This aircraft type has served many defence forces around the world over the past fifty years, as well as civil operators offering contracted services to state organisations (a popular choice when cost-saving or exposure to risk is sought by the states). The entering of the Lockheed Martin C-130 into civil registers has placed the type under the scrutiny of civil aviation regulators, such as the Federal Aviation Authority (FAA) in the United States (US) and the European Aviation Safety Agency (EASA) in Europe. For example, a search in the EASA safety publications tool [6] reveals a number of primary structure-related Airworthiness Directives (ADs) for the Lockheed Martin C-130 (Model 382). These EASA ADs are linked with previously issued FAA ADs, which offer further details on the type and the estimated cost for major structural repairs and inspections required for the aircraft wings (i.e., center wing box, CWB, and outer wing). One can observe the significant labour and part replacement costs involved in complying with these ADs (i.e., the CWB replacement cost is estimated at $\$ 5$ million and that of the outer wing at $\$ 8$ million, both per aircraft) [7]. It is interesting to note that the newer C-130J model is required to undertake similar maintenance tasks to ensure the integrity of the wing structure. For example, in 2017, the Royal Air Force (RAF) decided to retain as operational 14 of their C-130Js until 2035. For this, it was required to replace the aircraft CWBs, at a total cost of $\$ 143$ million [8]. This offers a flavour of the costs associated with legacy structural designs, heavy operational utilisation and the effect of heavy maintenance on the sustainment and affordability of older airlift types and fleets.

\section{New Airlifter Technical Considerations}

Assessing the long-term maintenance and sustainment costs of airlifters, i.e., 20, 25 or even 30 years from today, is important. There are various sources that can be used to inform the technical decision-makers, including the manufacturers, which can offer insight on the utilisation costs and publicly available research/industry reports, in conjunction with cost analysis and prediction models, i.e., [9]. For example, a report published by the RAND Corporation in 2013 provides, among others, a comprehensive analysis of the sustainment costs of US fleets of Lockheed Martin C-130 [10].

A "mix and match" strategy is especially important for small and diverse fleets, since these are more challenging and less cost-inefficient to run in comparison to more substantial size fleets. Any new aircraft type, including airlifters (given the much higher investment involved), should be evaluated 
against the existing technical support infrastructure, technical capability and fleet mix of the operator. An exercise evaluating different candidate airlift types can be very useful in this regard.

Developing and maintaining in-house technical support (and engineering) capability is essential not only for self-reliance purposes but also can be beneficial for sustainment cost-saving purposes. Efficient technical solutions, contributing to lower sustainment cost, can be sourced from defence engineers and technicians, and experience has shown that this can yield positive results for the operators. For example, aircraft fatigue monitoring programmes and inspection repair solutions are typically high-cost and value engineering capabilities. Moreover, the operator can interact in a more productive way with the aircraft manufacturer and external technical services' providers.

Learning from other users can be useful when evaluating new aircraft types. Experience of airlift users, especially for widely used types and models, offers valuable information on technical support matters. The sharing and exchange of technical information, data and findings, as well as practices that can have an effect on maintenance and sustainment, constitutes good practice for technical and engineering support purposes. This collective approach can also work for the benefit of operators when negotiating technical solutions with the aircraft manufacturer.

Dual certification and the airworthiness management framework can contribute (positively or negatively) indirectly to the maintenance and sustainment cost. This is related to the compliance requirements, since tailoring the certification standards (i.e., when an operator wishes to comply with non-typical requirements contained in widely used airworthiness codes) can increase the end-product cost. The European Military Airworthiness Requirements (EMARs) [11] were developed to bridge the gap between military-customised and civil certification requirements by adopting a common regulatory framework across different defence forces. Combining civil aviation regulatory structures and practice (where cost is an important element) with defence specific airworthiness requirements may offer to military operators the best of both worlds. In the case of airlifters, defence forces selecting dual-certified aircraft types have the opportunity to utilise these efficiently should such a hybrid airworthiness system be implemented. However, an operator can still operate dual-certified aircraft types, but it may be generally more onerous to manage technical support and ensure regulatory compliance when having to rely on bespoke contracts.

One option which military operators can also consider is civil-derivative or civil-certified airlifters. These aircraft types can be maintained under a civil or civil-based airworthiness framework. These aircraft can undergo maintenance and can be certified in EASA (or FAA) Part 145 aircraft maintenance organisations. This would offer cost benefits for the military operator and the defence and the civil aviation industry. In-country civil aircraft maintenance organisations would be able to offer their services to the defence force, expanding their business in the military aircraft maintenance sector. The same approach would also apply for the supply sector (spare parts and consumables), which can be sourced from a wider (non-defence specific) network/range of sources. Overall, this can have a positive effect on the sustainment cost of such (civil-derivative/civil-certified) airlifters.

The four pillars of technical support described in Figure 1 (supply, restoration and upgrade, engineering and regulatory compliance) can serve as a guide for identifying the technical considerations applicable to airlifters when evaluating the acquisition of new or used aircraft. These technical considerations have been mapped against the four pillars of technical support, presented in Figure 3 in a summarised way. 


\section{Sustainment}

\begin{tabular}{l|l|l|}
\hline \multicolumn{1}{|c|}{ Supply } & \multicolumn{1}{c|}{$\begin{array}{c}\text { Restoration \& } \\
\text { Upgrade }\end{array}$} & \multicolumn{1}{c|}{$\begin{array}{c}\text { Regulatory } \\
\text { Compliance }\end{array}$} \\
\hline $\begin{array}{l}\text { Long-term (20+ years) maintenance \& sustainment } \\
\text { costs }\end{array}$ & $\begin{array}{l}\text { Dual military - civil certified } \\
\text { aircraft covered by an }\end{array}$ \\
\hline $\begin{array}{l}\text { Type \& model best matching with existing infrastructure, fleet mix and technical } \\
\text { capability of the defence force }\end{array}$ & $\begin{array}{l}\text { Develop \& maintain sufficient level of in-house technical } \\
\text { airworthiness system }\end{array}$ \\
\hline $\begin{array}{l}\text { support capability } \\
\text { Experience from other military users - sharing \& } \\
\text { exchange of technical information }\end{array}$ & \\
\hline $\begin{array}{l}\text { Civil-derivative/certified aircraft maintained by civil (EASA Part 145) maintenance organisations in Ireland (and } \\
\text { overseas) \& wide network of supply networks }\end{array}$
\end{tabular}

*EMAR: European Military Airworthiness Requirements

Figure 3. Technical considerations for the evaluation of airlifters and mapping against the four pillars of technical support described in Figure 1.

\section{Conclusions}

This article has provided a general/broad view and discussion of technical considerations for the maintenance and sustainment of military transport aircraft (airlifters). In summary:

- Technical and engineering support can influence and influenced by the aircraft type and model choice;

- In-house capability and technical knowhow can be force-multipliers when it comes to achieving cost efficiency;

- Gaining experience from other aircraft users and creating synergies in exchanging technical information can be beneficial for maintenance and sustainment purposes;

- Airworthiness certification requirements for military aircraft are important considerations for older and newer aircraft types.

Funding: I have not received external funding.

Conflicts of Interest: I declare no conflict of interest.

\section{References}

1. Purton, L.; I Kourousis, K. Military Airworthiness Management Frameworks: A Critical Review. Procedia Eng. 2014, 80, 545-564. [CrossRef]

2. Marshall, Support Reimagined. Available online: https://marshalladg.com/capabilities/managed-services (accessed on 20 July 2020).

3. EASA Certifies the Airbus A400M. Available online: https://www.easa.europa.eu/newsroom-and-events/ press-releases/easa-certifies-airbus-a400m (accessed on 12 June 2020).

4. Navy Flight Demostration Squadron to Receive "Fat Albert" Replacement. Available online: https://www.navair.navy.mil/news/Navy-Flight-Demonstration-Squadron-receive-Fat-Albert-replacement/ Mon-06242019-1514 (accessed on 25 June 2020).

5. L-3 Communications' Spar Aerospace Awarded Contract by Hellenic Air Force to Upgrade C-130 Aircraft. Available online: http://www.defense-aerospace.com/article-view/release/9336/spar-wins-greek-c_ 130-upgrade-order-(mar.-26).html (accessed on 30 August 2020).

6. EASA Safety Publications Tool. List of Mandatory Continuing Airworthiness Information. Available online: https://ad.easa.europa.eu/ (accessed on 12 June 2020).

7. EASA Safety Publications Tool. US-2015-18-02: Wings-Center Wing Box (CWB) and Outer Wings-Replacement. Available online: https://ad.easa.europa.eu/ad/US-2015-18-02 (accessed on 30 August 2020). 
8. Centre Wing Box Replacement Deal Supports RAF's Hercules. Available online: https://www.flightglobal. com/centre-wing-box-replacement-deal-supports-rafs-hercules/124819.article (accessed on 25 August 2020).

9. Lappas, I.; Bozoudis, M. The Development of an Ordinary Least Squares Parametric Model to Estimate the Cost Per Flying Hour of 'Unknown' Aircraft Types and a Comparative Application. Aerospace 2018, 5, 104. [CrossRef]

10. McGarvey, R.; Light, T.; Thomas, B.; Sanchez, R. Commercial Intratheater Airlift, Cost-Effectiveness Analysis of Use in U.S. Central Command; RAND Corporation: Santa Monica, CA, USA, 2013.

11. European Defence Agency. Approved MAWA Documents. Available online: https://www.eda.europa.eu/ experts/airworthiness/mawa-documents (accessed on 30 August 2020).

(C) 2020 by the author. Licensee MDPI, Basel, Switzerland. This article is an open access article distributed under the terms and conditions of the Creative Commons Attribution (CC BY) license (http://creativecommons.org/licenses/by/4.0/). 